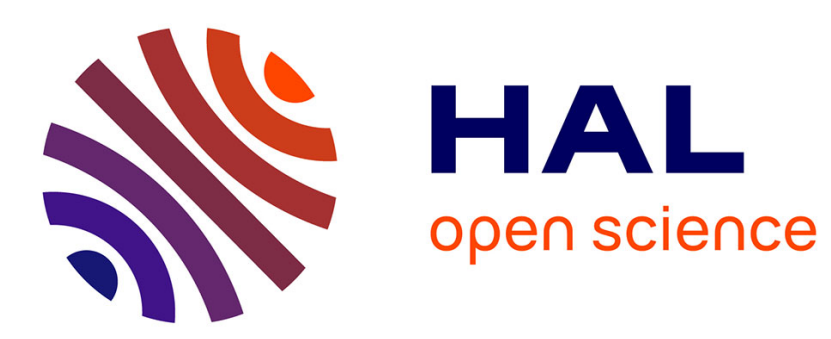

\title{
Two novel variants in the 3'UTR of the gene in familial breast and/or ovarian cancer
}

Stéphanie Lheureux, Bernard Lambert, Sophie Krieger, Angelina Legros, Dominique Vaur, Christophe Denoyelle, Pascaline Berthet, Laurent Poulain, Agnès Hardouin

\section{To cite this version:}

Stéphanie Lheureux, Bernard Lambert, Sophie Krieger, Angelina Legros, Dominique Vaur, et al.. Two novel variants in the 3'UTR of the gene in familial breast and/or ovarian cancer. Breast Cancer Research and Treatment, 2010, 125 (3), pp.885-891. 10.1007/s10549-010-1165-8 . hal-00577303

\section{HAL Id: hal-00577303 https://hal.science/hal-00577303}

Submitted on 17 Mar 2011

HAL is a multi-disciplinary open access archive for the deposit and dissemination of scientific research documents, whether they are published or not. The documents may come from teaching and research institutions in France or abroad, or from public or private research centers.
L'archive ouverte pluridisciplinaire HAL, est destinée au dépôt et à la diffusion de documents scientifiques de niveau recherche, publiés ou non, émanant des établissements d'enseignement et de recherche français ou étrangers, des laboratoires publics ou privés. 


\section{Two novel variants in the 3'UTR of the $B R C A 1$ gene in familial breast and/or ovarian cancer.}

Stéphanie LHEUREUX (1,2,3,4), Bernard LAMBERT (3), Sophie KRIEGER (2,3), Angelina LEGROS (2), Do min ique VAUR (2,3), Chris tophe DENOYELlE (3), Pascaline BERTHET $(2,4)$, Laurent POULAIN (3), Agnès HARDOUIN $(2,3)$.

(1): Département de recherche clinique, Centre de lutte contre le Cancer François Baclesse, Avenue du Général Harris, Caen, France

(2): Laboratoire de biologie clinique et oncologique, Centre François Baclesse, Avenue du Général Harris, Caen, France

(3): Un ité « Biologie et Thérapies Innovantes des Cancers Localement Agressifs » Groupe Régional d'Etudes sur le Cancer (GRECAN), IFR n 146 de l’Université de Caen, Basse-Normandie

(4): Oncologie médicale, Centre de Lutte contre le Cancer François Baclesse

\section{Corres ponding Author}

LHEUREUX Stéphanie Clinical research department François Baclesse Center Avenue du Général Harris 14000 CAEN - France

Tel : +33-2-31-45-50-02

Fax : +33-2-31-45-51-72

Mail : s.lheureux@baclesse.fr 


\begin{abstract}
For the majority of breast and/or ovarian cancer patients tested for BRCA1/2 genes, mutation screening of the coding regions remains negative. MicroRNAs which negatively regulate mRNA translation by binding to 3 ' untranslated region (3'UTR) are implicated in cancer. Genetic changes in the 3'UTR of several genes were reported to be associated with higher susceptibility to particular tu mor types. The aim of the present study was to analyze the BRCA1 3'UTR in patients tested negative for $B R C A 1 / 2$ deleterious mutations, in order to find variants implicated in the decrease of $B R C A 1$ expression through modification of miRNA binding.

Genotyping analyses were performed on genomic DNA of $70 B R C A$ negatives index cases, selected among patients with breast or ovarian cancer, less than 50 years old, with a strong family history. The co-occurrence of the identified variants with deleterious BRCAl mutations was then determined in a control population of 210 patients. A luciferase gene reporter assay was used to investigate the impact of the variants on the $B R C A l$ gene expression.

Two novel variants, c. $* 750 \mathrm{~A}>\mathrm{G}$ and c.*1286C $>\mathrm{A}$, were identified in the 3'UTR of BRCA1 gene, in two patients. The former was found three times in the control population, whereas the latter was absent. The used functional assay did not reveal any effect on the luciferase expression.

This study reveals a weak genomic variability in the 3'UTR of the BRCAl gene. All together, the results led us to classify the variant c. $* 750 \mathrm{~A}>\mathrm{G}$ as probably neutral, the variant $\mathrm{c} . * 1286 \mathrm{C}>\mathrm{A}$ re main ing unclassified.
\end{abstract}

\title{
Key words
}

Breast, ovarian, inherited cancer, 3'UTR, BRCA, miRNA 


\section{Introduction}

BRCA1 and BRCA2 genes are two inherited breast and/or ovarian cancer susceptibility genes [1;2]. A recent meta-analysis of ten studies estimated that the risk of developing breast cancer by age 70 years was $57 \%$ and $49 \%$ for $B R C A 1$ and BRCA2 mutation carriers, respectively. The corresponding risks for ovarian cancer were $40 \%$ and $18 \%$ [3]. As risk-reduction strategies, including chemoprevention and prophylactic surgeries, have been demonstrated to be effective in high-risk individuals [4], genetic testing for BRCA gene mutations has been increasingly utilized in clinical settings. The identification of mutation in these genes is extremely beneficial for patients pursuing risk reduction strategy and more recently for their cancer treatment. In fact, a novel class of promising drug, the PARP (poly ADP-ribose polymerase) inhibitors, is particularly effective in patients with $B R C A 1 / 2$ mutations [5]. These news drugs, like olaparib, are currently developed in this target $B R C A$ positive population [6;7]. Despite our understanding of the clinical phenotypes most predictive of the presence of $B R C A 1$ and $B R C A 2$ mutations, a lot of families with both breast and/or ovarian cancers do not have identifiable mutations [8]. About $80 \%$ of the mutation screening remains negative making the identification of the risk of developing a cancer difficult for the concerned families [9] and depriving the access to clinical trials. Most of the techniques used for genetic screening of $B R C A 1$ and $B R C A 2$ genes are performed by analysing the entire-coding region, including the intron-exon junctions, while introns and proximal untranslated regions remain unexplored. However, discovery of micro RNA (miRNA) has pointed out the important role of these untranslated regions in gene regulation. MicroRNAs are a class of small non-coding regulatory RNAs ranging in size from 17 to 25 nucleotides. They post-transcriptionnally repress expression of target genes by recognizing complementary sites mostly in their 3'untranslated region (3'UTR). Their expression deregulation has been implicated in the onset and progression of many diseases, including cancers [10].

In spite of the potential importance of the 3'UTR in gene regulation, the role of genomic variations in the 3'UTR of the tu mor suppressor BRCA1/2 genes remains unclear. Until now, few studies analy sed the 3'UTR of BRCA1 and most of them focused on the role of single nucleotide poly morphis ms (SNP) [11-14]. From Pongsavee et al., one SNP c.*421T/T (rs 8176318) seems to be linked to a decrease of BRCAl gene expression associated with an increased risk of cancer [12]. Authors proposed that the BRCAl gene expression alteration was the result of the creation of a new miRNA binding site by the SNP, although the link between both events has not been clearly established. However, to our knowledge, no mutation has been already described in the 3'UTR of BRCA1/2 genes. These observations led us to assume that unknown genomic variations in the 3'UTR of BRCA1/2 genes could be implicated in the inherited breast or ovarian cancer through their effect on $B R C A$ gene expression. In order to test this hypothesis, we analysed, in a first attempt, the BRCA1 3'UTR from patients tested negative for BRCA1 and BRCA2 mutations in highly selected families.

\section{Material and Methods}

Patient population

Genotyping analyses were performed on genomic DNA of 70 index cases selected from patients with breast or ovarian cancer diagnosed at an age of less than 50 years. These index cases had a strong history family at least on two generations: 3 breast cancers at first degree, one of which before 40 years, or 1 ovarian cancer as sociated 
with a breast cancer before 40 years. They have been tested negative for BRCA1 and BRCA2 mutations. Screening for BRCA1 and BRCA2 mutations was performed using two techniques, depending on the exons analyzed, i.e.denaturing High Performance Liquid Chromatography (dHPLC) and High Resolution Melting (HRM), both followed by direct sequencing. The screening methods for BRCA1 and BRCA2 large rearrangements were performed using a combination of the multiplex ligation-dependent probe amplification (MLPA) and quantitative multip lex PCR of short fluorescent fragments (QMPSF).

All patients have been selected from a database of families undergoing genetic counseling in the Western French Network. The patient gave signed informed consent.

\section{Control population}

The control group consisted of 210 unrelated probands with a BRCAl deleterious mutation. This population was chosen as control population to determine the frequency of the variants found in the 3'UTR. Arguing the fact that BRCAl compound heterozygotes for two deleterious mutations are embryonically lethal [15], this population was used to determine the frequency of the identified variants in $210 B R C A l$ wild type alleles. Moreover, the choice for this specific control population could allow to exclude the identified variant as a deleterious mutation if found in trans status with an other deleterious mutation. These patients were checked in our database between 1997 and 2009 and gave signed informed consent.

\section{Nomenclature}

The DNA sequence numbering is based on the cDNA sequence for BRCA1 (NCBI RefSeq NM_007294), following the recommendations of the Hu man Genome Variation Society (HGVS, translation initiation codon $\mathrm{ATG}=1)$.

PCR and sequencing

Patient peripheral blood samples were collected in EDTA tubes. Genomic DNA was isolated using an automated procedure (EZ1 DNA blood kit on biorobot EZ1 workstation, Qiagen, Hilden, Germany). The 3'UTR of BRCA1 gene (1376 bp) was studied in 4 overlapping frag ments about 500 nucleotides.

Each fragment was amplified by PCR (polymerase chain reaction) by a Taq Gold poly merase (Invitrogen Corporation, Madison, Carlsbad, California) with specific forward and reverse primers $(50 \mu \mathrm{M}$, Eurogentec, Liege, Belgium). These primers were tailed with M13 common sequences (50 $\mu \mathrm{M}$, Eurogentec) (Table 1).

PCR was performed with a commercial kit (Taq Gold poly merase, Invitrogen Corporation, Madison, Carlsbad, California), from $250 \mathrm{ng}$ of DNA. All amplifications were performed using a touch-down PCR program. The thermocycler parameters for PCR were $95^{\circ} \mathrm{C}$ for 10 minutes for the initial DNA poly merase activation, 26 cycles of $94^{\circ} \mathrm{C}$ for 20 seconds, $63^{\circ} \mathrm{C}$ for 20 seconds with a decrease of $0.5^{\circ} \mathrm{C} /$ cycle, and $72^{\circ} \mathrm{C}$ for 45 seconds, followed by 20 cycles of $94^{\circ} \mathrm{C}$ for 20 seconds, $50^{\circ} \mathrm{C}$ for 20 seconds and $72^{\circ} \mathrm{C}$ for 45 seconds, and a final extension at $72^{\circ} \mathrm{C}$ for 7 minutes. PCR products were separated by electrophoresis on a $1.5 \%$ agarose gel containing ethidium bromide and visualized by exposure to ultraviolet light. The amplified products were purified by ExoSap kit 
(USB Corp., Cleveland, Oh io, USA), accord ing to the manufacturer's instructions. The purified templates were sequenced in both directions with the M13 forward/reverse primers. A dye terminator cycle sequencing kit (Big Dye Terminator kit v1.1; Applied Biosystems) was used and templates analysed on an ABI 3130 sequencer (Applied Biosystems, USA).

HRM

HRM has only been performed for the exploration of the fragment 3 in the control population. Twenty ng of genomic DNA was added to a reaction master mix consisting of $1 \times$ LightCycler ${ }^{\circledR} 480$ High Resolution Melting Master (containing the proprietary ds-DNA saturating binding dye), with $2.5 \mathrm{mM} \mathrm{MgCl}_{2}$ (Roche Diagnostics, Germany) and $0.5 \mu \mathrm{M}$ of F3F and F3R (same PCR section). All the samples were performed under the same conditions in a 96-well plate in the LightCycler ${ }^{\circledR} 480$ Real-Time PCR System (Roche Diagnostics, Germany). The PCR program started with an initial denaturation step of $10 \mathrm{~min}$ at $95^{\circ} \mathrm{C}$, continued with 42 cycles of $15 \mathrm{~s}$ at $95^{\circ} \mathrm{C}, 15 \mathrm{~s}$ at $65^{\circ} \mathrm{C}$ with a decrease of $1^{\circ} \mathrm{C} /$ cycle and $25 \mathrm{~s}$ at $1 \mathrm{~min}$ followed by 10 cycles of $15 \mathrm{~s} \mathrm{at} 95^{\circ} \mathrm{C}, 15 \mathrm{~s}$ at $55^{\circ} \mathrm{C}$ and $25 \mathrm{~s}$ at $72^{\circ} \mathrm{C}$. To induce heteroduplexes formation, samples were heated to $95^{\circ} \mathrm{C}$ for $1 \mathrm{~min}$ and cooled to $40{ }^{\circ} \mathrm{C}$ for $1 \mathrm{~min}$. Samples were melted from $60{ }^{\circ} \mathrm{C}$ to $95{ }^{\circ} \mathrm{C}$ performing 25 acquisitions per $1{ }^{\circ} \mathrm{C}$. HRM melting curve analysis was performed using the Light-Cycler® 480 Gene Scanning software version 1.2 (Roche Diagnostics, Germany), which allows clustering the samples into groups on the basis difference plot obtained analyzing the differences in melting curve shapes. All the samples with a late amplification, as monitored by real-time PCR or associated with fluorescence of less than the $60 \%$ of the maximum, were excluded from the analysis. According to manufacturer's recommendations, unreliable melting profiles could be generated. All samples studied were clustered at the default sensitivity setting (0.3) with a pre-melt slider settings (100\% of fluorescence) between 85.9 and $86.4^{\circ} \mathrm{C}$ and post-melt slider settings ( $0 \%$ fluorescence) between 88.3 and $88.8^{\circ} \mathrm{C}$. Significant differences (ie $+/-2$ of relative signal differences) in fluorescence curves from the horizontal baseline were indicative of mutations. Results were confirmed by sequencing PCR products in the ABI Prism 3130 Genetic Analyser (Applied Biosystems, USA).

Determination cis/trans status of the doubly heterozygous c. [*750A $>\mathrm{G}(+) * 1286 \mathrm{C}>\mathrm{A}]$ variant

BRCA1 3'UTR was amplified using genomic DNA from the patient doubly heterozygous for the variants c. ${ }^{*} 750 \mathrm{~A}>\mathrm{G}$ and c. ${ }^{*} 1286 \mathrm{C}>\mathrm{A}$. Extension time and number of PCR cycles were determined in order to limit PCR-

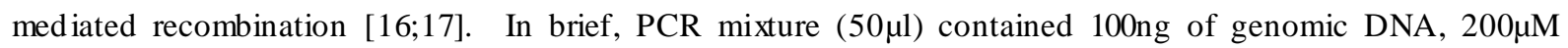
dNTP, the forward BRF 1 5'CTACGCGTCCCCACAGCCACTACTGA3' and reverse BRR1 primers

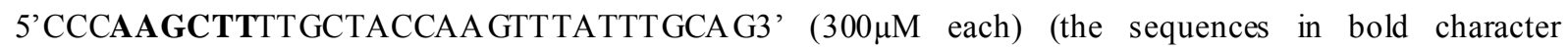
represent the MluI and HindIII restriction sites for BRF1 and BRR1 respectively) and 2.5U of Taq PHUSION (Finnzy mes). PCR program was undertaken for 1 cycle of $98^{\circ} \mathrm{C}$ (40s) followed by an annealing step of $58^{\circ} \mathrm{C}$ (30s) and an extension step of $72^{\circ} \mathrm{C}(80 \mathrm{~s})$. This first cycle was followed by 20 cycles of $98^{\circ} \mathrm{C}(30 \mathrm{~s}), 66^{\circ} \mathrm{C}(30 \mathrm{~s})$, $72^{\circ} \mathrm{C}(80 \mathrm{~s})$ and $1 \mathrm{cycle}$ of $72^{\circ} \mathrm{C}(2 \mathrm{~min} 30)$. After gel purification of PCR products, $3^{\prime}$-A overhangs were added to the blunt-ended 3'UTR fragment using the standard A-tailing protocol described by Promega. The 3'A-tailed 3'UTR frag ment was cloned into p GEMT easy vectors (Promega). Several clones were analyzed by sequencing. 
Luciferase reporter gene constructs

Contrary to what it was described above, in order to obtain the 4 possibilities of BRCA1 3'UTR containing the $750 \mathrm{~A}$ or $750 \mathrm{G}$ and $1286 \mathrm{C}$ or $1286 \mathrm{~A}$, we performed a BRCAl 3'UTR amplification under experimental conditions favouring the PCR-mediated recombination. For such a purpose, we performed the PCR with a shorter extension time (50s instead of 80s) for 35 cycles instead of 20. PCR products were purified, cloned into pGEMT easy vector and sequenced. Among the sequenced clones were retrieved clones with the wild type 3' UTR BRCAI (*750A;*1286C) (pGEMT-BRCA1-WT), the (*750G;*1286C) (pGEMT-BRCA1-750G), the $(* 750 \mathrm{~A} ; * 1286 \mathrm{~A})$ (pGEMT-BRCA 1-1286A) and the (*750G;*1286A) (pGEMT-BRCA1-750G/1286A). The generated plasmids were digested by MluI and HindIII, releasing a BRCAl frag ment containing the entire 3'UTR region (1376 bp). Each restricted fragment was inserted between the MluI and HindIII restriction sites of the pMIR-Report ${ }^{\mathrm{TM}}$ miRNA Expression reporter vector (Applied Biosystems). In such constructions all the BRCAI 3'UTR are immed iately downstream of the coding sequence of fire fly luciferase.

Dual luciferase assay

All transfections were performed using the JetPRIME ${ }^{\mathrm{TM}}$ transfection reagent (Poly-plus transfection). A breast cancer cell lines (MCF-7) and two ovarian cancer cell lines (SKOV3 and IGROV1) at 50-70\% confluence were transiently co-transfected with each pMIR-Report-BRCA1 construction (200ng) and the control reporter plas mid pRL-TK from Promega (20ng). pRL-TK contains a cDNA encoding Renilla luciferase, the expression of which is under the control of the thymidine kinase promoter. Luciferase assays were performed after $24 \mathrm{~h}$ using the Dual Luciferase reporter assay kit (Promega) and the luminometer Centro XS LB960 (Berthold Technologies) according to the manufacturer's instructions. Firefly luciferase activity was normalized relative to Renilla luciferase activity.

After $24 \mathrm{~h}$, the luciferase activ ity of each transfected population was compared with a wild type $(* 750 \mathrm{~A} ; * 1286 \mathrm{C})$ BRCA1 3'UTR pMIR construction (pMIR-BRCA 1-WT).

\section{Results}

Study population

Three polymorphis ms in the 3'UTR of BRCA1 were identified: c.*421G>T (rs8176318) with genotype frequencies $0.53,0.11$ and 0.36 for $\mathrm{G} / \mathrm{G}, \mathrm{T} / \mathrm{T}$ and $\mathrm{G} / \mathrm{T}$ respectively, c.*1287C $>\mathrm{T}$ ( rs 12516) with genotype frequencies $0.53,0.11$ and 0.36 for $\mathrm{C} / \mathrm{C}, \mathrm{T} / \mathrm{T}$ and $\mathrm{C} / \mathrm{T}$ and $\mathrm{c} . * 1332 \mathrm{G}>\mathrm{A}$ (rs8176320) found heterozygous in only two patients.

The polymorphism c. $* 421 \mathrm{G}>\mathrm{T}$ was always associated with the polymorphis $\mathrm{m}$ c. ${ }^{*} 1287 \mathrm{C}>\mathrm{T}$ in our study population.

Two novel variants c.*750 $\mathrm{A}>\mathrm{G}$ and $\mathrm{c} . * 1286 \mathrm{C}>\mathrm{A}$ were described for the first time, confirmed on two independent blood tests. Patient A was diagnosed with bilateral breast cancer at 40 and 44 years and presented the variant $\mathrm{c} . * 750 \mathrm{~A}>\mathrm{G}$ (Figure $1 \mathrm{~A})$. Patient $\mathrm{B}$ was diagnosed with breast cancer at 33 years and presented both 
the c. $* 750 \mathrm{~A}>\mathrm{G}$ and the c. $* 1286 \mathrm{C}>\mathrm{A}$ variant (Figure 1B). The patients $\mathrm{A}$ and $\mathrm{B}$ were homozygous for the two polymorphis ms c.*421G/G and c.*1287C/C. These results are summarized in table 2.

Control Population

The c. ${ }^{* 750 A}>\mathrm{G}$ variant was screened by HRM. The frag ment 3 of the 3'UTR of BRCA1 was also sequenced in the control population. Three women with three different types of deleterious mutations presented this variant in the 210 patients tested $(1.4 \%)$. The c.* $1286 \mathrm{C}>\mathrm{A}$ variant was screened by sequencing analysis. This variant was not found in the control population.

Determination cis/trans status of the doubly heterozygous c. [*750A $>\mathrm{G}(+) * 1286 \mathrm{C}>\mathrm{A}]$ variant

The study of 19 clones from the patient B showed that the variants $\mathrm{c} . * 750 \mathrm{~A}>\mathrm{G}$ and $\mathrm{c} . * 1286 \mathrm{C}>\mathrm{A}$ were localized in cis on the same allele (Figure 2).

Functional as say

In order to determine whether the c.*750A $>\mathrm{G}$ and/or the c.*1286C $>\mathrm{A}$ base substitutions in the BRCA1 3' UTR could alter gene expression, MCF-7 breast cancer cells were transfected with luciferase reporter plas mids containing either one base substitution (pMIR-BRCA 1-750A, pMIR-BRCA 1-1286C) or both (pMIR-BRCA 1$750 \mathrm{~A} ; 1286 \mathrm{C})$. The results showed that the presence of $\mathrm{c} . * 750 \mathrm{~A}>\mathrm{G}$ and/or $\mathrm{c} *{ }^{*} 1286 \mathrm{C}>\mathrm{A}$ does not alter the lucife rase expression (Figure 3). The same results were obtained using SKOV3 and IGROV1 ovarian cancer cell lines as recipient cells (data not shown).

Bioanalys is

Analyses of miRNA binding sites on BRCAl 3'UTR were performed using microRNA.org (http://www.microrna.org/microrna/home.do), microinspector (http://www.imbb.forth.gr/mic roinspector.) and RegRNA (http://regrna.mbc.nctu.edu.tw) softwares. No human miRNA binding site has been ide ntified in the zone of interest for the variant c. $* 750 \mathrm{~A}>\mathrm{G}$. For the variant c. $* 1286 \mathrm{C}>\mathrm{A}$, the base substitution increased slightly the binding of several miRNAs. The potential miRNAs were different according to the bioinformatic softwares and the defined thresholds for the free energy change.

\section{Discussion}

This is one of the first published studies which identified variants in the 3'UTR of BRCA1. Two novel variants c. ${ }^{*} 750 \mathrm{~A}>\mathrm{G}$ and c. ${ }^{*} 1286 \mathrm{C}>\mathrm{A}$ were identified in the $3^{\prime} \mathrm{UTR}$ of $B R C A 1$ gene in 2 patients from 70 inde $\mathrm{x}$ cases non $B R C A 1 / 2$ mutation carriers selected for high probability of inherited predisposition. For the doubly heterozygous patient, we showed clearly that the variants $c * 750 \mathrm{~A}>\mathrm{G}$ and $\mathrm{c} . * 1286 \mathrm{C}>\mathrm{T}$ were localized in cis on the same alle le. 
The variant $c . * 750 \mathrm{~A}>\mathrm{G}$ was found three times in the control population associated to three different deleterious mutations, thereby probably localized in trans with each mutation. It induced no alteration of luciferase expression in the functional as ay and did not create any potential miRNA binding sites. All these results suggest that this variant has probably no impact on the BRCAl expression.

The lack of association of the variant c.*1286C $>$ A with another deleterious mutation was evocative of a potential deleterious character. This hypothesis was reinforced by the bioinformatics analysis which shows that it increases the binding of several miRNAs on the BRCA1 3'UTR. Conversely, its presence immediately downstream of the coding sequence of firefly luciferase gene, either alone or in association with the variant c. $* 50 \mathrm{~A}>\mathrm{G}$, did not induce any effect on the expression of this reporter gene in three cell lines. This observation would suggest this variant is not able to modulate BRCAl expression through modified miRNA binding. However, although the functional testing was carried out on three different cancer cell lines, one cannot completely exclude that the miRNAs identified by bioanalysis could be absent from the tested cell lines thus leading to a false negative result. Such cell specific miRNA expression was already observed by Pongsavee $e t$ al. [12]. The authors tested the BRCAl gene expression alteration induced by the SNP c.*1287T/T (rs 12516) on three different breast cell lines. A weak inhibitor effect was only observed in MCF-7 cells $(p=0.044)$ [12]. Finally, one cannot also rule out the hypothesis that the absence of the variant $\mathrm{c} *{ }^{*} 1286 \mathrm{C}>\mathrm{A}$ in the control population or its presence in one patient among 70 is the result of chance. Thus, without further studies, it seems difficult to conclude on the potential biological effect of the c.*1286C>A variation.

Nevertheless, one has to notice that the sequencing of the 3'UTR of BRCA1 from 68 over 70 high selected patients did not reveal any variant in this region. This weak genomic variability, as also observed by Puget et al. [14], suggests that the creation of new miRNA binding sites in this region is not a major mechanism to alter the BRCAl gene expression. Recently, a study revealed that a SNP, associated with an increased risk of breast cancer, could positively regulate the expression of the BRCA1 gene through modified binding of a miRNA in the coding region of this gene [13]. Futhermore, genetic variants in miRNA genes, targeting the 3'UTR of BRCA1, can potentially alter the regulation of this gene although their impact on the genetic susceptibility to breast cancer remains to be determined [18-20].

It is a real challenge to identify inherited mutations in such patients with a strong family history, to propose an adaptive follow-up for them and their family. Therefore, in families with a strong history of breast cancer, other studies must be performed on the other regions of BRCA gene which are still unexplored, including the 3'UTR of $B R C A 2$. The increased risk of hereditary breast cancer is not only the result of the alteration of the $B R C A$ genes expression [21]. The search for the implication of other genes would beneficiate from high throughput methods of analys is [22].

In conclusion, the screening of the 3'UTR of BRCA1 in 70 patients with a strong family history of breast or ovarian cancer revealed two novel variants. The variant c. $* 750 \mathrm{~A}>\mathrm{G}$ alone could be identified as neutral. The variant c. ${ }^{*} 1286 \mathrm{C}>\mathrm{A}$ remains unclassified and did not allow us to bring a clear element decision-making for use in routine. 


\section{Acknowledgments}

Authors are very grateful to Professeur P. Gauduchon and Dr. M. Tosi for their helpful discussions.

\section{References}

1. Miki,Y., Swensen,J., Shattuck-Eidens,D., Futreal,P.A., Harshman,K., Tavtigian,S., Liu,Q., Cochran,C., Bennett,L.M., Ding,W., and . (1994) A strong candidate for the breast and ovarian cancer susceptibility gene BRCA 1. Science, 266, 66-71.

2. Wooster,R., Bignell,G., Lancaster,J., Swift,S., Seal,S., Mangion,J., Collins,N., Gregory,S., Gu mbs,C., and Micklem,G. (1995) Identification of the breast cancer susceptibility gene BRCA2. Nature, 378, 789-792.

3. Chen,S. and Parmigiani,G. (2007) Meta-analysis of BRCA1 and BRCA 2 penetrance. J.Clin.Oncol., 25, 1329-1333.

4. Robson,M. and Offit,K. (2007) Clinical practice. Management of an inherited predisposition to breast cancer. N.Engl.J.Med., 357, 154-162.

5. Hennessy,B.T., Timms ,K.M., Carey,M.S., Gutin,A., Meyer,L.A., Flake,D.D., Abkevich,V., Potter,J., Pruss,D., Glenn,P., Li,Y., Li,J., Gonzalez-Angulo,A.M., McCune,K.S., Markman,M., Broaddus,R.R., Lanchbury,J.S., Lu,K.H., and Mills,G.B. (2010) So matic Mutations in BRCA 1 and BRCA2 Could Expand the Number of Patients That Benefit From Poly (ADP Ribose) Poly merase Inhibitors in Ovarian Cancer. J.Clin.Oncol. .

6. Audeh,M.W., Carmichael,J., Penson,R.T., Friedlander,M., Powell,B., Bell-Mc Guinn, K.M., Scott,C., Weitzel,J.N., Oakn in,A., Lo man,N., Lu,K., Sch mutzler,R.K., Matulonis,U., Wickens,M., and Tutt,A. (2010) Oral poly(ADP-ribose) poly merase inhibitor olaparib in patients with BRCA1 or BRCA2 mutations and recurrent ovarian cancer: a proof-of-concept trial. Lancet.

7. Tutt,A., Robson,M., Garber,J.E., Do mchek,S.M., Audeh,M.W., Weitzel,J.N., Fried lander,M., Arun,B., Lo man,N., Sch mutzler,R.K., Wardley,A., Mitchell,G., Earl,H., Wickens,M., and Carmichael,J. (2010) Oral poly(ADP-ribose) poly merase inhibitor olaparib in patients with BRCA1 or BRCA2 mutations and advanced breast cancer: a proof-of-concept trial. Lancet.

8. Ford,D., Easton,D.F., Stratton,M., Narod,S., Goldgar,D., Devilee,P., Bishop,D.T., Weber,B., Lenoir, G., Chang-Claude,J., Sobol,H., Teare,M.D., Struewing,J., Arason,A., Scherneck,S., Peto,J., Rebbeck,T.R., Tonin,P., Neuhausen,S., Barkardottir,R., Eyfjord,J., Lynch,H., Ponder,B.A., Gayther,S.A., ZeladaHed man,M., and . (1998) Genetic heterogeneity and penetrance analysis of the BRCA1 and BRCA2 genes in breast cancer families. The Breast Cancer Linkage Consortium. Am.J.Hum.Genet., 62, 676689.

9. Fackenthal,J.D. and Olopade,O.I. (2007) Breast cancer risk as sociated with BRCA1 and BRCA2 in diverse populations. Nat.Rev.Cancer, 7, 937-948.

10. Nilsen,T.W. (2007) Mechanisms of micro RNA-mediated gene regulation in animal cells. Trends Genet., 23, 243-249.

11. Kontorovich,T., Levy,A., Korostishevsky,M., Nir,U., and Fried man,E. (2010) Single nucleotide polymorphis ms in miRNA binding sites and miRNA genes as breast/ovarian cancer risk modifiers in Jewish high-risk wo men. Int.J.Cancer, 127, 589-597.

12. Pongsavee,M., Yamkamon,V., Dakeng,S., charoenrat,P., Smith,D.R., Sau nders, G.F., and Patmasiriwat,P. (2009) The BRCA1 3'-UTR: 5711+421T/T_5711+1286T/T genotype is a possible breast and ovarian cancer risk factor. Genet.Test.Mol.Biomarkers, 13, 307-317. 
13. Nicoloso,M.S., Sun,H., Spizzo,R., Kim,H., Wickramasinghe,P., Shimi zu,M., Wojcik,S.E., Ferd in,J., Kunej,T., Xiao,L., Manoukian,S., Secreto,G., Ravagnani,F., Wang,X., Radice,P., Croce,C.M., Davuluri,R.V., and Calin,G.A. (2010) Single-nucleotide poly morphis ms inside micro RNA target sites influence tumor susceptibility. Cancer Res., 70, 2789-2798.

14. Puget,N., Stoppa-Lyonnet,D., Sin ilnikova,O.M., Pages,S., Lynch,H.T., Leno ir,G.M., and Mazoyer,S. (1999) Screening for germ-line rearrangements and regulatory mutations in BRCA 1 led to the identification of four new deletions. Cancer Res., 59, 455-461.

15. Liu,C.Y., Flesken-Nikit in,A., Li,S., Zeng, Y., and Lee,W.H. (1996) Inactivation of the mouse Brca 1 gene leads to failure in the morphogenes is of the egg cylinder in early postimplantation development. Genes Dev., 10, 1835-1843.

16. Meyerhans,A., Vartanian,J.P., and Wain-Hobson,S. (1990) DNA recomb ination during PCR. Nucleic Acids Res., 18, 1687-1691.

17. Judo,M.S., Wedel,A.B., and Wilson,C. (1998) Stimu lation and suppression of PCR-mediated recomb ination. Nucleic Acids Res., 26, 1819-1825.

18. Shen,J., A mbrosone,C.B., and Zhao,H. (2009) Novel genetic variants in micro RNA genes and familial breast cancer. Int.J.Cancer, 124, 1178-1182.

19. Gao,L.B., Bai,P., Pan,X.M., Jia,J., Li,L.J., Liang,W.B., Tang,M., Zhang,L.S., Wei,Y.G., and Zhang,L. (2010) The association between two polymorphis ms in pre-miRNAs and breast cancer risk: a metaanalysis. Breast Cancer Res.Treat..

20. Catucci,I., Yang,R., Verderio,P., Pizzamiglio,S., Heesen,L., Hemminki,K., Sutter,C., Wappenschmidt,B., Dick,M., Arnold,N., Bugert,P., Niederacher,D., Meindl,A., Sch mutzler,R.K., Bartram,C.C., Ficarazzi,F., Tizzoni,L., Zaffaroni,D., Manoukian,S., Barile,M., Pierotti,M.A., Radice,P., Burwinkel,B., and Peterlongo,P. (2010) Evaluation of SNPs in miR-146a, miR196a2 and miR-499 as low-penetrance alle les in German and Italian familial breast cancer cases. Hum.Mutat., 31, E1052E1057.

21. Campeau,P.M., Foulkes,W.D., and Tischkowitz,M.D. (2008) Hereditary breast cancer: new genetic developments, new therapeutic avenues. Hum.Genet., 124, 31-42.

22. Walsh,T., Lee,M.K., Casadei,S., Thornton,A.M., Stray,S.M., Pennil,C., Nord,A.S., Mandell,J.B., Swisher,E.M., and King,M.C. (2010) Detection of inherited mutations for breast and ovarian cancer using genomic capture and massively parallel sequencing. Proc.Natl.Acad.Sci.U.S.A, 107, 1262912633 


\section{Tables captions}

Table 1: Primers for the amplification of 4 overlapping frag ments from the 3'UTR of the $B R C A 1$ gene The primers were designed in order to have specific sequences of the 3'UTR of the BRCA1 gene (in bold) downstream to M13 sequences (in italic).

Table 2: Genomic variations in the 3' UTR of the BRCA1 gene

The sequencing of the 3'UTR allows the identification of three poly morphisms (for comparison the frequency in the European panel is shown) and 2 novel variants.

\section{Figures captions}

Fig 1: The identification of the novel variants $\mathrm{c} . * 750 \mathrm{~A}>\mathrm{G}$ and $\mathrm{c} . * 1286 \mathrm{C}>\mathrm{A}$ by sequencing anal ysis (A) Forward sequencing of patient A frag ment 2 containing the c. $* 750 \mathrm{~A}>\mathrm{G}$ variant; (B) Reverse sequencing of patient $\mathrm{B}$ frag ment 4 containing the $\mathrm{c} *{ }^{*} 1286 \mathrm{C}>\mathrm{A}$ variant.

Fig 2: Cis/trans status determination of the doubly heterozyg ous c. [*750A>G (+) $* 1286 \mathrm{C}>\mathrm{A}]$ variant The 3'UTR of the BRCAl gene was amplified from the genomic DNA of the patient doubly heterozygous for the variants c.*750A $>$ G and c.*1286C $>$ A. A mplified 3'UTR was cloned and sequenced.

(V): variant; (WT): wild type

Fig. 3: Determination of the effect of $c .750 A>G$ and $/$ or $c *{ }^{*} 1286 C>A$ variants on gene expression by the luciferase gene reporter assay.

Luciferase levels were measured from MCF-7 cells transfected with pMIR-BRCA1-WT, pMIR-BRCA 1-750G, pMIR-BRCA1-1286A and pMIR-BRCA1-750G/1286A plasmids as described. Data are expressed as Means +/Standard Deviation of three independent experiments. 
A

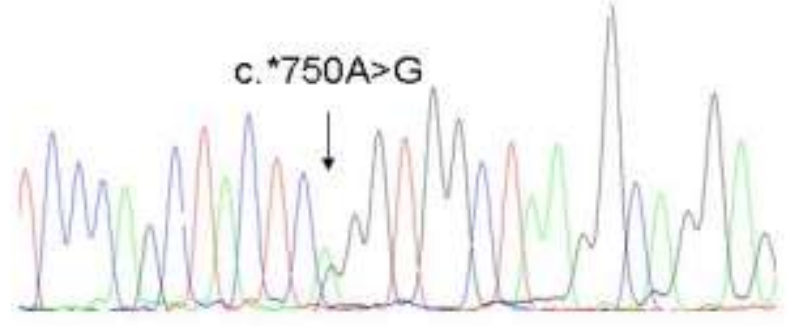

B

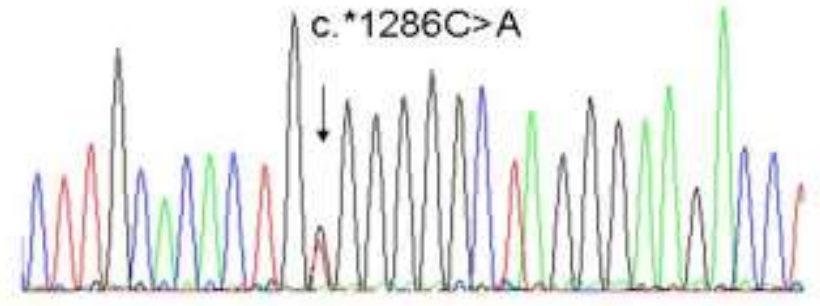

Fig 1 
BRCA1 3'UTR
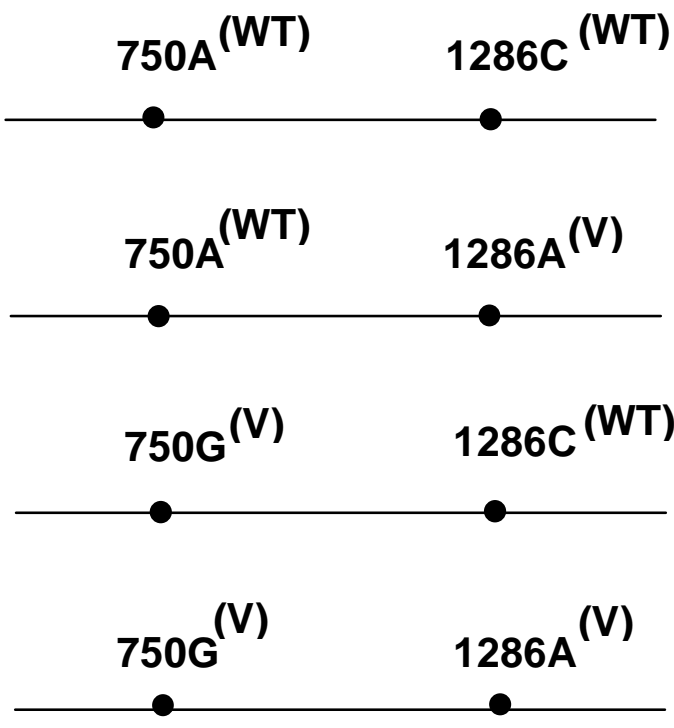

Number of clones

( $N=19)$

$10(53 \%)$

0

0

$9(47 \%)$

Fig 2

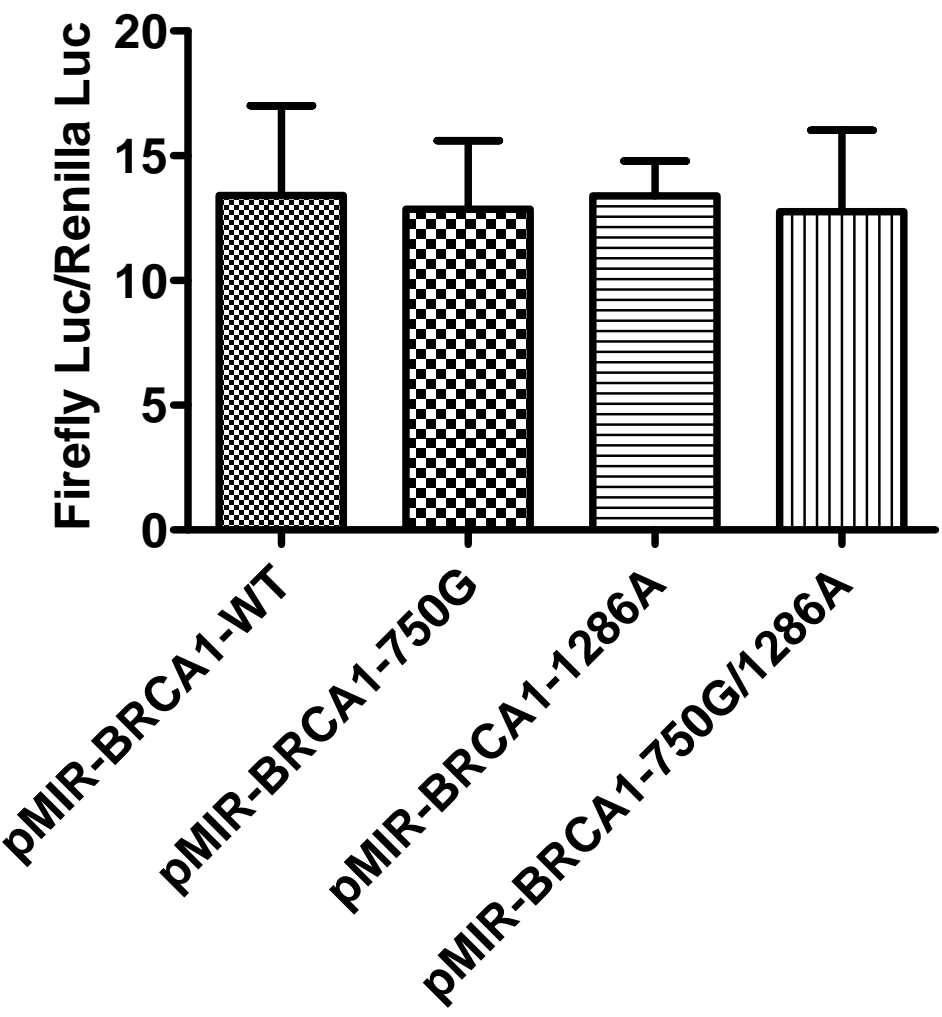


Fig 3

\begin{tabular}{c|c}
\multicolumn{1}{c|}{ Fragment } & \multicolumn{1}{c}{ M13 primer } \\
\hline Fragment 1 Forward & GTAAAACGACGGCCAGTATCCCCCACAGCCACTACT \\
Fragment 1 Reverse & AACAGCTATGACCATGTGAGAACTGCCCAAGGACT \\
Fragment 2 Forward & GTAAAACGACGGCCAGTGCTGTTGTTGGCTTAGGGC \\
Fragment 2 Reverse & AACAGCTATGACCATGCTGGAGTGCCGTGGTATGA \\
Fragment 3 Forward & GTAAAACGACGGCCAGTTGAAACCCCATCTCTACTAA \\
Fragment 3 Reverse & AACAGCTATGACCATGATCACCTCAAAGAAAGAAC \\
Fragment 4 Forward & GTAAAACGACGGCCAGTATCATACCACGGCACTCCAG \\
Fragment 4 Reverse & AACAGCTATGACCATGTGTTTGCTACCAAGTTTATT
\end{tabular}

Table 1

\begin{tabular}{|l|l|l|l|}
\hline & Genomic variation & $\begin{array}{c}\text { Frequency } \\
(70 \text { patients })\end{array}$ & $\begin{array}{l}\text { Frequency in } \\
\text { European panel }\end{array}$ \\
\hline
\end{tabular}




\begin{tabular}{|c|c|c|c|}
\hline SNP & c. ${ }^{*} 421 G>T$ & $25(35,7 \%)$ & $45,8 \%$ \\
\hline SNP & c.*421G/G & $37(52,9 \%)$ & $37,5 \%$ \\
\hline SNP & c. ${ }^{*} 421 \mathrm{~T} / \mathrm{T}$ & $8(11,4 \%)$ & $16,7 \%$ \\
\hline$\overline{\mathrm{SNP}}$ & c. $^{*} 1287 \mathrm{C}>\mathrm{T}$ & $25(35,7 \%)$ & $47,8 \%$ \\
\hline SNP & c. ${ }^{*} 1287 \mathrm{C} / \mathrm{C}$ & $37(52,9 \%)$ & $39,1 \%$ \\
\hline$\overline{\mathrm{SNP}}$ & c. ${ }^{*} 1287 \mathrm{~T} / \mathrm{T}$ & $8(11,4 \%)$ & $13 \%$ \\
\hline SNP & $c^{*}{ }^{*} 1332 \mathrm{G}>\mathrm{A}$ & $2(2,9 \%)$ & $2,4 \%$ \\
\hline Variant & c.*750A>C & $2 / 70(2.8 \%)$ & \\
\hline Variant & c. ${ }^{*} 1286 C>A$ & $1 / 70(1.4 \%)$ & \\
\hline
\end{tabular}

Table 2 